\title{
Additional Technical Training on Telecommunications Engineering Sciences
}

\author{
Flávio Jorge $^{1, *}$, Paula Cardoso ${ }^{2}$ \\ ${ }^{1}$ Instituto de Telecomunicações, Universidade de Aveiro, Aveiro, Portugal \\ ${ }^{2}$ Instituto de Telecomunicações, Aveiro, Portugal \\ *Corresponding author: flaviojorge@ua.pt
}

Received September 09, 2014; Revised October 18, 2014; Accepted October 29, 2014

\begin{abstract}
The Telecommunications Engineering Sciences are presented as an embracing field of studies with central importance on both scientific and technological development, and cuts across many areas of knowledge, such as maths and physics. Recognizing this value, the Instituto de Telecomunicações together with the Universidade de Aveiro developed already several projects among hundreds of high school students, following the main goal of spread scientific knowledge on Telecommunications Engineering. The first one, entitled Tele-Loucuras, followed the philosophy "hands on the mass", and the full results obtained through an inquiry are evaluated, proving the importance of these kinds of initiatives to the students' additional technical training. Following this project, a second one raised entitled Atreve-te!, which followed a more theoretical philosophy, but addressed more than a thousand students. A qualitative assessment to the project performance is presented based on the feed-back received. Also following the first project, a third one also raised entitled Radio, Antennas and Space Propagation, which is a summer course covering the physical layer of the Telecommunications Engineering, since the radio channel to the radio equipment and radio systems and a qualitative assessment to this initiative is also performed based on the experience and feed-back received from the students.
\end{abstract}

Keywords: Telecommunications, Electronics, Engineering, high school, additional training

Cite This Article: Flávio Jorge, and Paula Cardoso, "Additional Technical Training on Telecommunications Engineering Sciences." American Journal of Educational Research, vol. 2, no. 10 (2014): 963-969. doi: 10.12691/education-2-10-17.

\section{Introduction}

The human being needs to be connected with each other since ever, even at distance. For this reason, the Telecommunications Engineering Sciences are an embracing field of studies assuming a central position on both scientific and technological development, cutting across many areas of knowledge, such as maths and physics. Their practical and innovative character opens the door to the creativity and challenge of their professionals, actively contributing to adding value to any country and to the world.

The Telecommunications are responsible for a strong social and economic impact. On the one hand they enable a rapprochement between people and a facilitated access to the information and on the other hand are responsible for the production of essential goods and services in a modern society.

Recognizing the value of this field of studies, this paper aims to report on three initiatives developed for high school students by the Instituto de Telecomunicações together with the Universidade de Aveiro (Tele-Loucuras, Atreve-te! and Radio Antennas and Space Propagation), all of them following the main goal of spread the scientific knowledge by providing additional technical training on this field. Additionally, assuming the same purpose (additional technical training for high school students) and methodology, the first two projects were the first longterm projects ever carried out in Portugal by a University, so opening the door to other future ones. The IEEE is already developing five similar activities around the world promoting the critical thinking, engineering spirit and increasing the students' interest in pursuing an engineering-related career. More information regarding these IEEE initiatives can be found in [1]. Regarding the third project, the Universidade do Porto have a similar program, but none related to Telecommunications Engineering [2]. The Universidade de Lisboa also have a similar program with a course on Information Technologies, where in a single demonstrative activity the Telecommunications are referred [3]. In concerning other Universities, the common training offer lies in Sciences, as math, physics, chemistry or biology or even on Human and Social Sciences [4].

The first project, named Tele-Loucuras, which is the equivalent in English of Tele-Craziness, raised in order to fight the almost absence of technical training for the Science and Technologies' high school students since 2006, after the high school curriculums' revision in Portugal. More than two hundred students carried out practical activities covering several subjects on Telecommunications Engineering. The results obtained 
through an inquiry were evaluated and were quite promisors. This project was described preliminarily in [5].

Following the previous project, a second one, named Atreve-te!, which is the equivalent in English of Dare Yourself!, raised in order, not to fulfill the necessity of practical training as the Tele-Loucuras, but the increasing necessity of clarification among the high school students of what's engineering, what's the engineer's role as both a professional and a society member and what's underlying the development of any innovative product, service or even model. This project addressed more than a thousand students and a very good qualitative feed-back was obtained, encouraging the development of similar activities in the future. This project was also described preliminarily in [6].

The third one is a summer course entitled Radio, Antennas and Space Propagation, and is also devoted to the high school students. It aims to cover all the physical layer of the wireless communications, since the radio channel, to the radio systems, and has already two editions successfully completed among tens of students.

Compared to other similar initiatives, when it's possible, these projects actively contribute to the additional technical training of the participating students by offering them the opportunity to have, not only lectures, but also laboratory activities and, above all they allowed the students to design and develop several kind of Telecommunication Engineering projects from scratch, facing the real challenges by assuming the Engineer's position.

\section{The Tele-Loucuras}

\subsection{The Team}

The project was developed as a partnership between the Aveiro's pole of the Instituto de Telecomunicações (ITAv), the Departamento de Electrónica Telecomunicações e Informática of the Universidade de Aveiro (DETI-UA) and the Amateurs Radio group of the Electronics, Telecommunications and Telematics Association of the same department (NRAETTUA), was coordinated by the author and was concretized by the author together with António Soares (DETI-UA MSc. Student) and Nuno Carvalho (DETI-UA Full Professor).

\subsection{Project Description}

Inserted into one of the main goals of the IT-Av, transferring knowledge to the society, the Tele-Loucuras arises from the idea of spread scientific knowledge on Electronics and Telecommunications Engineering, providing additional technical training on this field of studies to the high school students of the Science and Technologies course.

The activities should be attractive, fun, assuming, at the same time, a serious pedagogical character, promoting the challenge, critical thinking and teamwork, characteristics of the engineering professional.

Thus, the development of simple practical activities was proposed, having, at the same time, enough content allowing to learn surrounded by a relaxed atmosphere.

These activities were developed for three hours with a break of fifteen minutes. At each school, two classes were addressed, one in the morning and another in the afternoon, each of them having around thirty students.

On each intervention, the project was presented and the activity was briefly explained, stating the essential contents for the theoretical understanding of what would be developed. Hence, the implementation of the activities was carried out by teams of two or three, occasionally four students, who developed the proposed project, exposing their difficulties during the activity, which were mitigated by the team. All of the projects were then tested and validated at the end of each session.

After each session, the participants were asked to complete a short inquiry, allowing the team to make a progressive evaluation of the project and even acquiesced to some suggestions in the course of time, improving from one school to the next one the quality of the TeleLoucuras.

\subsection{Technical and Promotional Kits}

To each student was given a technical kit, which was composed of the components needed to develop the activity. To each student was offered also a promotional kit, this one composed by a certificate of attendance, a quality inquiry, a project flyer, a DETI-UA flyer, and a Summer Academy flyer, since the students could find on this summer courses an opportunity of carrying out other similar activities to the one proposed in this project, for instance the Radio, Antennas and Space Propagation, everything package in a DETI-UA case. To the teachers were offered the same material, the UA magazine, a pencil and a bookmark. In the Figure 1 we can see both the technical and promotional kits.

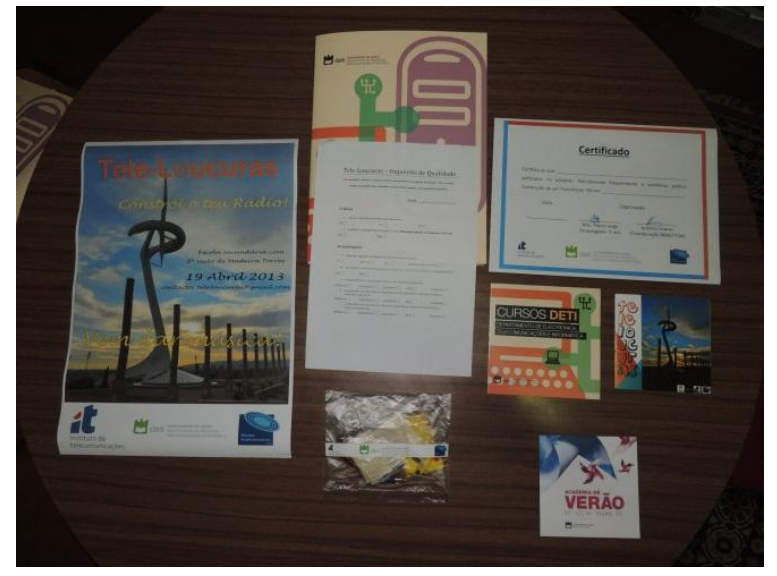

Figure 1. Tele-Loucuras technical and promotional kits

\subsection{Proposed Activity}

The proposed activity was a simple, but functional, FM transmitter, which can be easily found on the internet, actually spread for several websites, to which we made some technical modifications in order to improve its quality, but keeping the original circuit design [7].

It's a complete circuit, since it's composed by all the fundamental electrical components, for instance, resistors, capacitors, transistors, and even an inductor, which should be constructed by the students. Thus, from a large variety of components without any meaning, from the perforated plate, audio jack, wires, and electrical components, following a given procedure the students could develop, 
from nothing, a complete and functional RF circuit and hear in a commercial radio the music which was generated from, for example, their mobile phones, and transmitted by their projects.

Issues like audio generation, signal modulation and amplification, antennas design, circuit analysis and physical implementation details were addressed.

Thus, the circuit proved to be challenging and attractive, being also efficient in printing a high degree of satisfaction and achievement by those who made it happen.

This circuit can be found in the Figure 2.

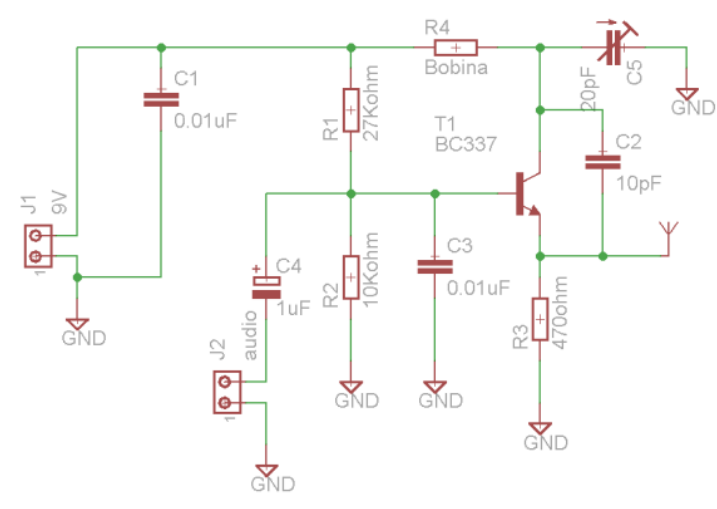

Figure 2. Tele-Loucuras proposed circuit

\subsection{Inquiries Analysis and Results}

The schools which participated in this initiative were the Escola Secundária c/ $3^{\circ}$ ciclo de Madeira Torres in Torres Vedras, Escola EB 2,3/S de Vale de Cambra, in Vale de Cambra, Escola Secundária Serafim Leite, in S. João da Madeira and Escola Secundária de Arouca, in Arouca.

The 250 collected inquiries were filtered on a make sense basis, in order to get reliable results. Taking $75 \%$ of the collected inquiries, which were considered as valid, $41.1 \%$ of the students who took part of this project were from the $10^{\text {th }}$ grade, $36.4 \%$ from the $11^{\text {th }}$ grade and $22.5 \%$ from the $12^{\text {th }}$ grade, as we can see in Figure 3, and among the students from the $12^{\text {th }}$ grade, $95.2 \%$ were attending the Physics course.

\begin{tabular}{|l|l|}
\hline & Which year are you attending? \\
\hline 2.5 & \\
\hline
\end{tabular}

Figure 3. Students distribution according to the attending grade. $41.1 \%$ from the 10th grade, $36.4 \%$ from the 11 th grade and $22.5 \%$ from the 12 th grade

The theoretical exposure of the activity was evaluated as Good by $53.5 \%$ of the students, Satisfactory to $15.5 \%$, Unsatisfactory to $0.5 \%$ and was considered Excellent by $30.5 \%$ of the participants, as we can see in the Figure 4. Also, the practical component of the activity was evaluated as Good by $52.4 \%$ of the students, Satisfactory to $9.1 \%$, Unsatisfactory to $0.5 \%$ and was considered Excellent by $38 \%$ of the participants, as we can see in the Figure 5. From these results we can see a shift of the results' distribution from the theoretical evaluation to the practical evaluation, putting in evidence that globally the students prefer to put their hands on the mass than attend a lecture about the theoretical subjects.

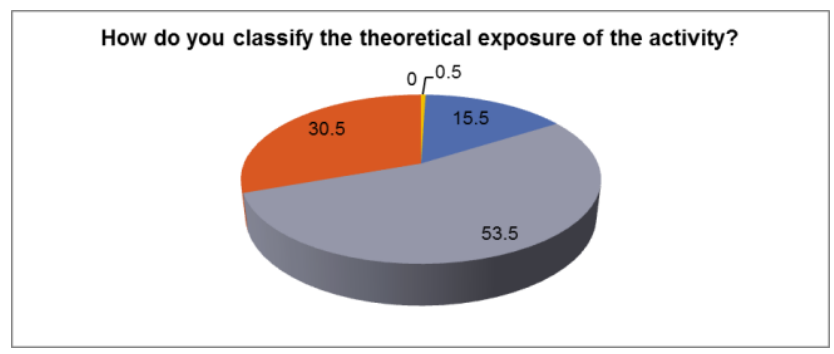

Figure 4. Classification of the theoretical component. Excellent for $30.5 \%$, Good for $53.5 \%$, Satisfactory for $15.5 \%$ and Unsatisfactory for $0.5 \%$

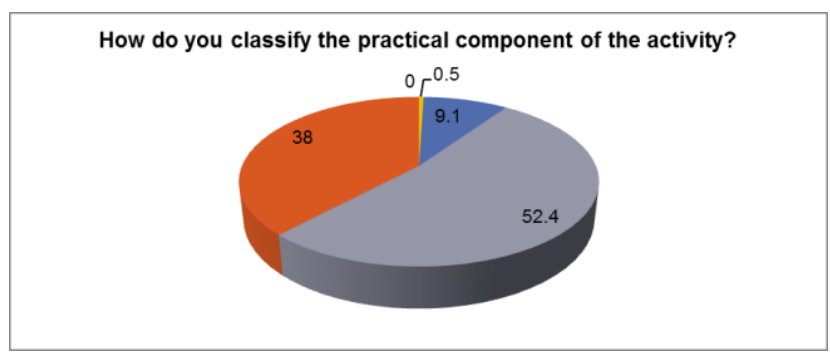

Figure 5. Classification of the practical component. Excellent for $38 \%$, Good for $52.4 \%$, Satisfactory for $9.1 \%$ and Unsatisfactory for $0.5 \%$.

Globally the activity was considered as Good by $60.4 \%$ of the students, as Satisfactory by $6.4 \%$ of the students, as Unsatisfactory by $0.5 \%$ and Excellent by $32.7 \%$, as presented in Figure 6.

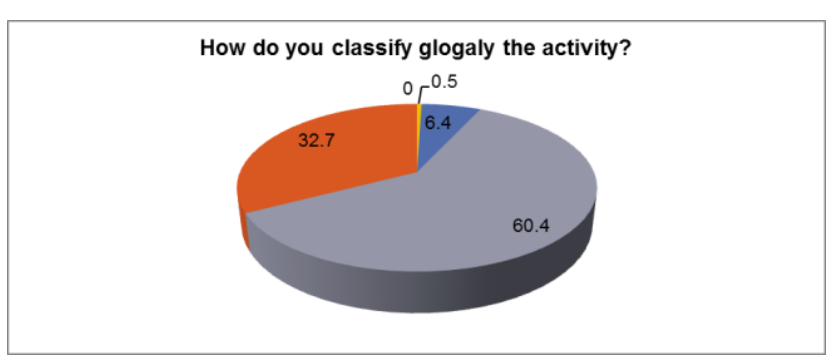

Figure 6. Global evaluation of the activity. Excellent for $32.7 \%$, Good for $60.4 \%$, Satisfactory for $6.4 \%$ and Unsatisfactory for $0.5 \%$

Meanwhile, $94.1 \%$ of the students showed interest in participating in other similar activities, against $5.9 \%$ who answered negatively to the same question, as we can see in Figure 7.

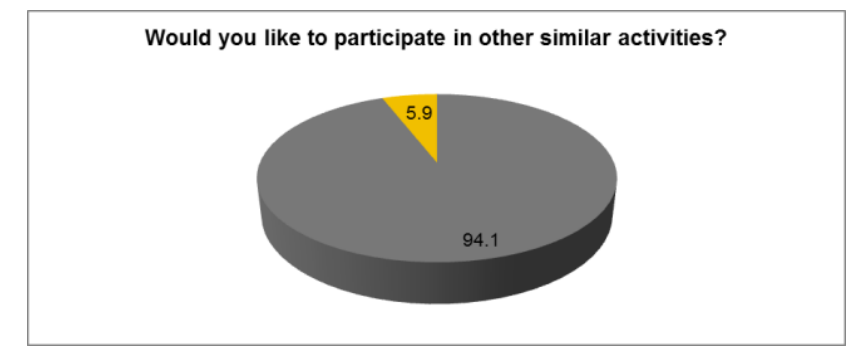

Figure 7. Participation in other similar activities. Yes for $94.1 \%$ and No for $5.9 \%$

Finally, $90.4 \%$ of the students stated that the project contributed to their additional technical training, against 
9.6\% who kept indifferent to this main goal, as we can see in Figure 8.

In your opinion, this activity allowed you to get additional technical training?

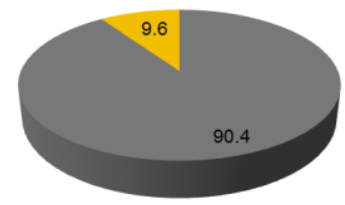

Figure 8. Evaluation of the additional technical training. Yes for $90.4 \%$ and No for $9.6 \%$.

Based on the results obtained, this project was considered a success among both students and teachers, who welcomed the team due to the originality and innovation.

\subsection{Dissemination}

The project was disseminated through the internet, in the Facebook and in a website which was dedicatedly developed (http://teleloucuras.wix.com/teleloucuras). Also, articles both in the UA Online Journal [8] and QSP radio magazine [9] were published arousing the interest of radio Antena 1, carrying out an interview to the Click programme [10]. The School TV of Vale de Cambra also published a report based on the project flyer, and the Madeira Torres propagated the project through all the school libraries in Portugal [11].

\section{The Atreve-te!}

\subsection{The Team}

The project was developed as a partnership between the IT-Av and the DETI-UA. The project was coordinated by the author and concretized by the author together with Paula Cardoso (IT-Av collaborator), Tiago Alvané (DETIUA MSc. Student), Nuno Carvalho (DETI-UA Full Professor) and other colleagues who have interest in spreading knowledge among young people, Gil Fernandes (IT-Av Researcher) and Tiago Varum (IT-Av Researcher).

\subsection{Project Description}

The world without engineers would be some kind of mess, but not always we can recognize both the value and effort of these professionals. The technology evolved so quickly that now the evolution is given as granted, appearing to be quite normal to have, for example, at each year more advanced cell phones, able of giving response to the most demanding services and, if something goes wrong, people seem to be unable to recognize the work which is behind of that technology. If this is true for the people in general, this is even truer when we talk about young students, who want to watch films, to listen music and surf through the social networks, anywhere, anytime.

For these reasons, the project Atrave-te! aims to bring among the high school students the engineering as a challenge field of studies, which should be capable of give response to the problems of a society and also the engineers' role as both professionals and people of the society, so the project should clarify what is the engineering, what the engineer as professional do and both the social and economic impact of the engineering around all of us.

Following these main goals, in this project participated more than one thousand and hundred students of Vilar Formoso, Mira, Guarda, Fornos de Algodres, Nelas, Vila Nova de Gaia, Sever do Vouga, Oliveira de Azeméis, Castro Daire, Porto, Albergaria-a-Velha, Tondela, Gafanha da Nazaré, Vouzela, Oliveira de Frades, S. João da Madeira, Cantanhede, Arouca and Marques de Castilho.

The implementation on the field occurred through a talk between an engineer and the students and, for one hour, topics related to the engineering were discussed.

The definition of Engineering was presented first as being talent and contrivance. The necessity of solving problems found in the society was stressed then. For solving those problems the engineer should be armed with several important qualities such as communicational and team work skills, logical thinking, practical and objective approach to the problems found, so how the engineers think, were aspects open to the discussion.

The world without engineers was discussed and the importance of the mechanical, electrical, telecommunications, electronics, informatics, civil and acoustic engineering was presented.

Meanwhile, since the engineer should propose solutions to several kinds of problems, the complete chain, since the problem identification, to the solution's proposal was discussed. Aspects such as creativity to have an idea, research in order to establish a procedure to be implemented during the development process in laboratory, manufacture or present the final solution and, finally commercial aspects were exhaustively discussed in order to get an insight into what is behind the development of any novel product, service, process, technique or even model.

In order to allow the students to concretize the true engineer's role, several projects in electrical, electronics and telecommunications engineering were presented. The first one aims to improve the public illumination with LED technology, which should reduce the power consumptions by adjusting the illumination in function of the ambient and turned on when's necessary. Economic and environmental aspects were stressed here. The second one is related to the development of an intelligent device, capable of be a radio, TV or even a cell phone, and the third aims to improve the mobile network for the fifth generation. Thanks to this project it's possible to stress the needs to have more bandwidth and be capable of give response to the most demand services which the clients want, clients like ourselves and the students. The remote control, free of batteries, was a project presented next, and here environmental aspects were stressed again, together with the fact of all of us are just right now exposed to several kind of radiation, which could be used to charge batteries or even to put devices to work without these batteries. The fiber technology was also presented as an important field of studies capable of give us greater TV and internet quality. Another project presented was a social network to vehicles, which aims to help drivers to get a safer driving experience, since if a car gets broken a repair shop is automatically informed, together with the other drivers in the neighbourhoods. Also, if a car has an 
accident, both the authorities and the drivers in the neighbourhoods are notified, assisting immediately the passengers and preventing accidents, specialty if reduced visual conditions occur. The necessity of modelling the Earth-Satellite communications channel in order to improve the satellite communications system, leading to the services cost reduction was discussed and following this project, another one regarding the implementation of electronic devices for space applications was presented. Since the experiment, which is now aboard of the Alphasat satellite, aims to test in real scenario the behaviour of a new transistors' design and its immunity to the background cosmic radiation, a project in radio astronomy was presented together with the importance of this field of studies.

At the end of the discussion, the students were warned to their own role in the society as being the future researchers and engineers responsible of get answers to the world around us, so they should prepare their selves to the future challenges.

A practical demonstration of an ongoing project was presented and the students were invited to ask whatever question they would like to see clarified.

\subsection{Practical Demonstrations}

Two practical demonstrations were presented. One of them is a project that involves a quadcopter. Some technical details regarding the project were given to the students while the quadcopter was just flying, always guaranteeing the security of everyone in the room. The software that is being developed combining hardware will receive a GPS signal and a predefined route should be followed. This route will be a GPX file that will be created on Google Earth or other similar software, allowing the marking of way points and saving them in GPS data files. When receiving the GPS coordinates, the software should convert them in control commands recognized by the drone, performing the autonomous flight. This know-how was transmitted to the students for a better understanding about how it becomes a solution and then a product, like many of the other projects already discussed. Finally, some examples about civil applications were specified to the students. Also, practical issues and constraints found during the development were presented from the engineer's point of view and the approaches taken face to those problems were discussed.

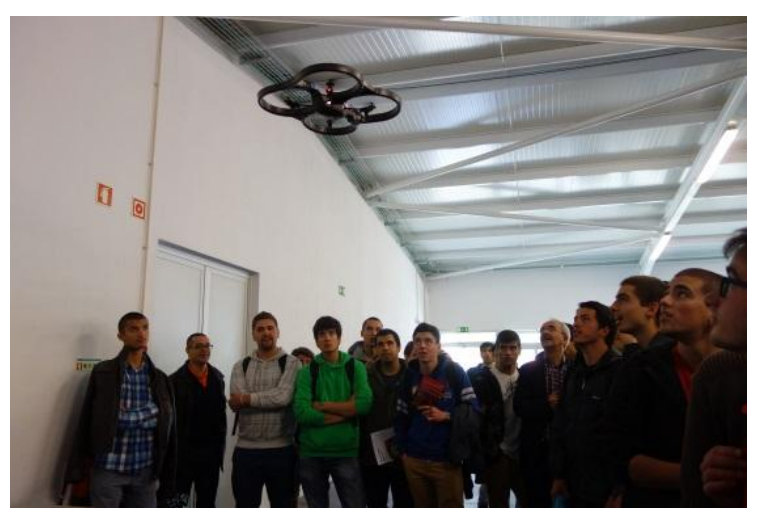

Figure 9. Practical demonstration example

Another one was an educational kit used to explain the fiber technology. Aspects such as light propagation on a fiber, reflection, refraction, and impairments found on the propagation medium and how to overpass these last ones using for instance amplification were some aspects explored using this kit.

\subsection{Promotional Kits and Dissemination}

To each student is given a promotional kit, this one composed by a project flyer, a DETI-UA flyer, and a Summer Academy flyer, everything package in a DETIUA case. To the teachers is offered the same material, the UA magazine, a pencil and a bookmark.

The project was disseminated through the internet, via facebook and UA Online Journal, who carried out na article about the Atreve-te!.

Also a project website was later on developed (http://atreve-te.wix.com/atreve-te).

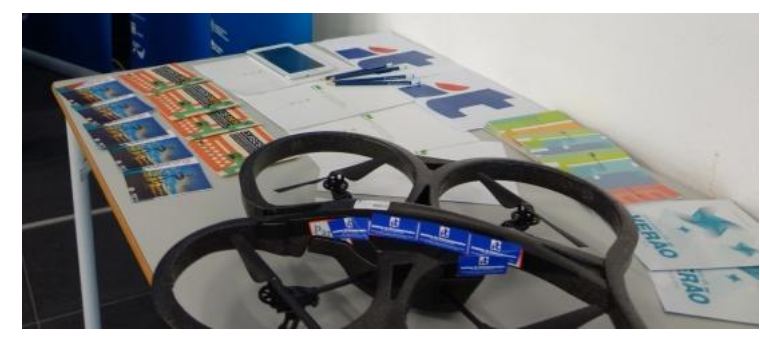

Figure 10. Atreve-te! promotional kits example

\subsection{Feed-back and Final Analysis}

The feedback was truly good. Both the students and the professors got interested in this and other similar initiatives, since it helps the students to get an insight into what is this concept of engineering, as disclosed as yet so poorly explained, and also into what is being done now at the laboratories.

We realize that the students got committed with this project, since they actively participate and asked interesting questions regarding their possible future careers in engineering. In spite of our main example be the telecommunications engineering, since it's the field which we feel more comfortable with, we should stress that the engineering in general was discussed.

The practical demonstrations were a very good complement to the lecture, since they caused a great impact among the students, who like to see it happening.

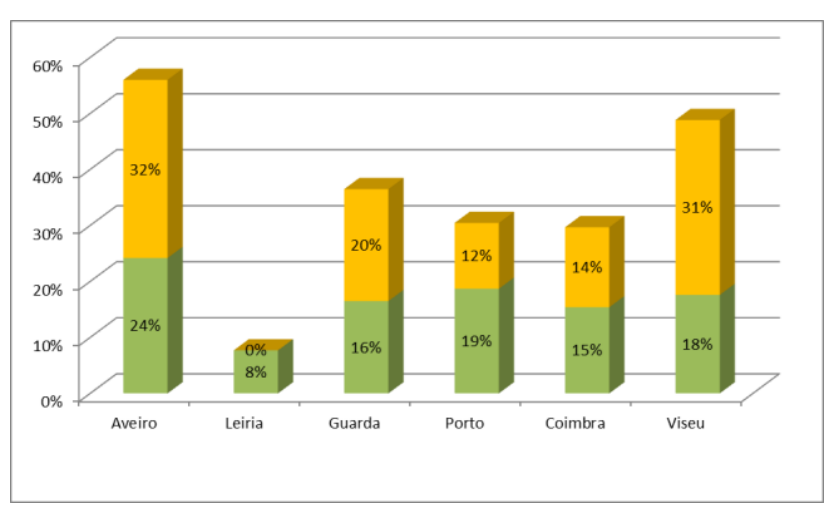

Figure 11. Distribution of the contacted schools function of district in green and from those contacted the percentage who effectively participated and received the project

From the 91 contacted schools, only 19 of them, so $21 \%$, answered positively and received the project, which 
puts in evidence how hard is to have the schools' door opened as we can see in Figure 11. The lower values are the distribution of the contacted schools, so for instance, $24 \%$ of the contacted schools were from Aveiro's district. The upper values are the percentage of schools at each district who received the project, so for instance in Aveiro only $32 \%$ of the contacted schools received the project. However, it should be noted that the project acceptance problem could be attenuated or even avoided if the project planning began in September, while schools are defining their own annual activities' plan, and not in April, while schools are already preparing their selves to the final and national exams.

\section{The Radio, Antennas and Space Propagation}

\subsection{The Team}

The Radio, Antennas and Space Propagation is a summer course developed under the Summer Academy of the Universidade de Aveiro. In this academy, the students can attend both a scientific and social programme. During a week, the first one occurs from 9 AM to 5 PM with a break for lunch, and the second one from 5 PM. The author is the head of this course, but is also a professor together with Armando Rocha (DETI-UA Assistant Professor), Nuno Carvalho (DETI-UA Full Professor), Domingos Barbosa (IT-Av Researcher), Hugo Mostardinha (IT-Av Laboratory Assistant), Miguel Bergano (IT-Av Researcher), António Soares (DETI-UA MSc. Student), Jorge Ruivo (DETI-UA MSc. Student and NRAETTUA Coordinator) and Nicolas Neto (DETI-UA MSc. Student and NRAETTUA Vice-Coordinator).

\subsection{Feed-back and Project Description}

The Radio, Antennas and Space Propagation aims to offer students the opportunity to receive additional technical training on the physical layer of the wireless communications, so subjects like radio wave propagation, antennas design, radio and radio systems are all covered.

The course had already two successfully editions and several tens of students took this course as a serious opportunity to learn what is far away from their possibilities in the high school. From lectures with experts on the field, to laboratory classes, design and development projects and field trips, all of these components were welcomed by the students, who stated that could learn much more in this course than in other ones, which they attended in other areas and/or institutions.

The first edition was dedicated to the Wi-Fi Radio System and the second one to the Satellite Communication Systems.

Under the radio wave propagation subject, were covered aspects such as electromagnetic spectrum, radio wave propagation phenomena depending on the frequency, from tens of $\mathrm{KHz}$ to tens of $\mathrm{GHz}$, wave polarization, transmission lines, adaptation and channel variability. A special attention was given in the first edition to the indoor propagation and in the second one to the earthspace propagation.

Regarding the antennas subject, in both editions aspects such as antenna definition and characterization, antennas design, antennas polarization and antennas analysis and testing were covered. In the first edition the students were asked to develop a Bi-Quad antenna to $2.4 \mathrm{GHz}$, which was tested in an anechoic chamber. A polarization test and a critical comparison between the developed antenna and the one proposed by the manufacturer was also performed. Regarding the second edition, the development of a Satellite Ground Station antenna for NOAAs satellites was proposed and tested both in laboratory and in real scenario later on.

In both the editions the radio astronomy was presented as an important field of studies. Its definition, state-of-theart and several undergoing projects at the global scale were presented. The wireless power transmission and the radiofrequency identification were subjects also under discussion at the same time that the students were developing their own wireless power transmission circuit based on a self-oscillator. Furthermore, a historical perspective of the radio evolution, from its beginning to the actual existing technologies and future perspectives to both the software defined radio and the cognitive radio were given.

Meanwhile, in the first edition the students could visit the IT-Av and have a complete insight into the telecommunications world, but in the second one they could visit a mobile ground station and have an insight into the mobile radio system. In both editions the students could understand also another nonprofit version of radio, the one carried on by amateurs who do research and development on propagation, antennas, radio equipment and necessary accessories. The application of this version on the civil protection and support for emergency and public calamity was also put in evidence.

Regarding the first edition, the students developed a power meter, which was later on used together with the developed Wi-Fi antenna and, making use of the knowledge acquired during the propagation subject, they were invited to start a fox hunt, in which they should map the library routers in the minimum possible time. On the other hand, in the second edition the students mounted a complete and functional satellite ground station based on a SDR, using their own antennas and the knowledge acquired during the week. The station was able of receive on live a NOAA satellite signal and present in a computer the image which was being transmitted.

Below we can see some photos regarding the antennas development and testing.

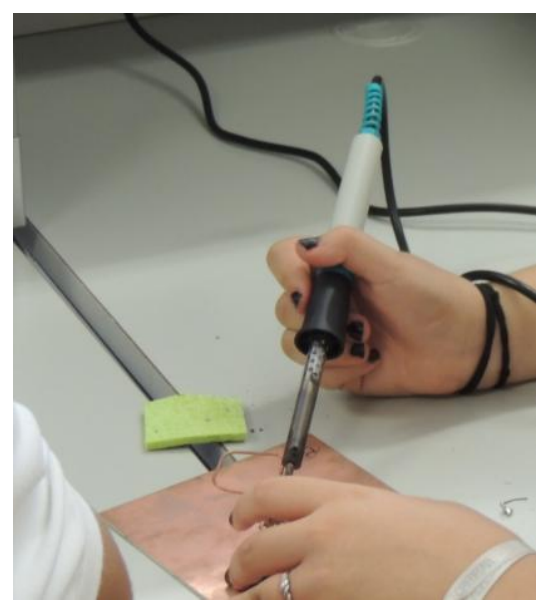

Figure 12. Antennas development 


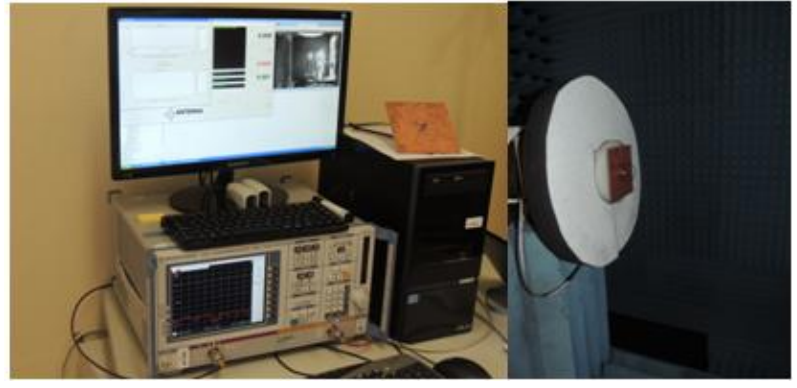

Figure 13. Antennas testing

And below we can see a student developing his power meter, welding all the necessary components.

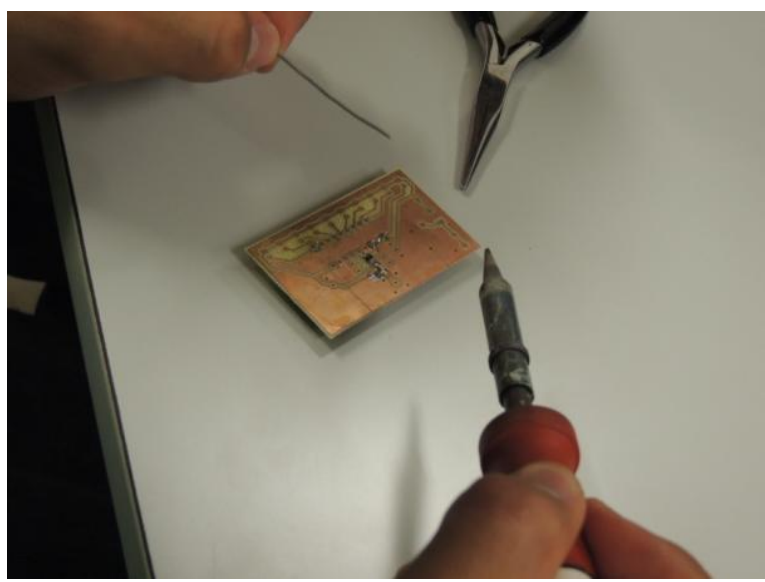

Figure 14. Power meter development

\section{Conclusion}

The paper reported on the first three long-term projects ever made by a Portuguese University focused on providing specifically additional technical training for high school students. In conclusion, the Universities' investment on providing additional technical training for high school students is important and recognized by this community.

The Tele-Loucuras addressed more than two hundred students who faced the challenges of engineering and, based on the results obtained, we consider this project a success among both students and teachers, who welcomed us due to the originality and innovation.

The Atreve-te! addressed more than one thousand and hundred students, who could understand what engineering means and what's the engineer's role as both a professional and a society member. In spite of all the participants give a good feed-back, many troubles concerning the schools acceptance could be avoided if the planning started in the beginning of the school year in September.

The Radio, Antennas and Space Propagation addressed already more than two tens of students who faced the most different problems found in Telecommunications Engineering. From lectures with experts to design, development and construction of RF equipment and RF systems mounting, all the activities were welcomed by the students, who recognized in this summer course a serious opportunity to learn about subjects which they could never found in their own schools.

\section{Acknowledgement}

As a final state, despite these initiatives be important to the high school students, even to high school professors who also took part of these with enthusiasm, it should be stressed the hard work behind of them, and none of these initiatives could happen without the huge effort from every team member.

The author and the teams responsible for the implementation of these projects would also like to acknowledge the IT-Av, the DETI-UA, the NRAETTUA and as well all of those who directly or indirectly were involved in these initiatives, for their helpfulness, which was fundamental in order to reach the complete success in these projects, specially the Engineer João Pedro Madaleno Pereira for his commitment with the Atreve-te!.

\section{References}

[1] http://www.ieee.org/education_careers/education/preuniversity/epi cs_high.html, visited 17-Oct-2014.

[2] http://universidadejunior.up.pt/, visited 17-Oct-2014.

[3] http://www.ulisboa.pt/sociedade/verao-na-ulisboa14, visited 17Oct-2014/.

[4] http://noticias.universia.pt/destaque/noticia/2011/07/06/842483/un iversidades-atacam-com-universidades-vero.html, visited 17-Oct2014.

[5] Jorge, F. M. S., Soares, A. X. F., Carvalho, N. B., Tele-Loucuras: Hands on Telecommunications Engineering Sciences in $11^{\text {th }}$ International Conference on Hands-on Science, Aveiro, 2014.

[6] Jorge, F. M. S., Cardoso, P. C. L., Alvané, T. A. G., Carvalho, N. B., Atreve-te!: Dare Yourself to the World of Engineering in $11^{\text {th }}$ International Conference on Hands-on Science, Aveiro, 2014.

[7] http://wiki.radiolivre.org/Manuais/MiniTransmissorFM, visited 11-Jun-2014.

[8] http://uaonline.ua.pt/pub/detail.asp?c=33890\&lg=en, visited 17Oct-2014.

[9] http://www.qsprevista.com/, visited 17-Oct-2014.

[10] http://www.rtp.pt/programa/radio/p3053, visited 17-Oct-2014.

[11] http://teleloucuras.wix.com/teleloucuras\#!media/c1ghi, visited 17Oct-2014. 